\title{
Der Bauernkrieg. Ein Systemkonflikt an der Wende vom Mittelalter zur Neuzeit
}

\author{
Florian Ambach \\ Kerngebiet: Neuzeit \\ eingereicht bei: assoz.-Prof. Mag. Dr. Elena Taddei \\ eingereicht im: WiSe 2017/18 \\ Rubrik: SE-Arbeit
}

\begin{abstract}
The Peasants' War. A system conflict on the watershed between the Middle Ages and the Early Modern era

The following paper aims to examine if and how the Peasants' War was connected with the Protestant Reformation. In order to answer this question, various models of society developed by the peasants will be analysed. The specific characteristics of the different, loosely connected rebellions, which were summarised and idealised to a united movement, the so-called Peasants' War, by later historiography, will be pointed out through the example of four different rebellious areas.
\end{abstract}

\section{Einleitung}

In dieser Arbeit soll der Frage nachgegangen werden, ob und inwiefern der Bauernkrieg der Jahre 1524 bis 1526 mit der Reformation zusammenhängt. Dabei soll insbesondere auf die verschiedenen Verfassungsentwürfe und Gesellschaftsmodelle der Bauernkriegszeit eingegangen und herausgearbeitet werden, in welchen Ideen der Einschlag der Reformation festgestellt werden kann.

Unerlässlich ist die Klärung zentraler Begriffe, auf die im Rahmen der Arbeit zurückgegriffen wird. DerTerminus Bauernkrieg impliziert die Vorstellung eines einheitlichen und zusammenhängenden Krieges, in dem es klare Frontlinien gegeben habe. Dem war allerdings nicht so, da die Aufstände meistens nur lokale Gültigkeit hatten und sich auf 
das unmittelbar betroffene Gebiet beschränkten. Der Problematik, wie die einzelnen Unruhen zusammenhingen und welche Rolle herrschaftsübergreifenden Programmen zukam, soll im Laufe der Arbeit nachgegangen werden. Überdies ignoriert der Begriff die Tatsache, dass es schon im Spätmittelalter eine Reihe von Aufständen gegeben hatte.' Er suggeriert, dass die Bauernschaft alleine beteiligt war und bagatellisiert die Bedeutung der Knapp- und Bürgerschaft sowie des niederen Adels. In vielen Publikationen wurde der Begriff durch den Verweis, dass bürgerliche Schichten vielerorts den Bauernkrieg anführten, problematisiert.2 Aus diesen Gründen scheint es angebracht, den Terminus in dieser Arbeit kursiv zu setzen.

Die erste wissenschaftliche Auseinandersetzung mit dem Thema entstand 1795 vom Göttinger Universitätsprofessor Georg Friedrich Sartorius ${ }^{3}$ unter dem Titel „Versuch einer Geschichte des deutschen Bauernkrieges".4 Unter dem Eindruck der Französischen Revolution stehend, sollte das Werk durch den Hinweis auf die Kräfte des Volkes eine Warnung an die Obrigkeiten sein. Sartorius sah in der Reformation nicht die Ursache des Bauernkriegs, wohl aber bezeichnete er sie als dessen Auslöser. Der Historiker Leopold von Ranke ${ }^{5}$ nannte den Bauernkrieg "das größte Naturereignis des deutschen Staates", allerdings in einem negativen Sinn, wenn er kommentiert, dass der „Fanatismus der schwärmerischen Predigt [...], der die Zerstörung rechtfertigte, sich berufen glaubte, Blut zu vergießen und nach der Eingebung des Momentes, die er für göttlich erklärte, ein neues himmlisches Reich aufzurichten." ${ }^{17}$ Ganz anders als Rankes Interpretation ist jene des protestantischen Theologen Wilhelm Zimmermann. ${ }^{8}$ Er berief sich auf Ferdinand Friedrich Oechsles ${ }^{9}$ "Beiträge zur Geschichte des Bauernkrieges in den schwäbisch-fränkischen Grenzlanden", in denen die Versuche der Bürger*innen und Bauern sowie Bäuerinnen, eine Verfassung zu entwerfen, lobend hervorgehoben worden waren. ${ }^{10}$ Als Abgeordneter der Frankfurter Nationalversammlung - er zählte zur äußersten Linken - legte Zimmermann in der emotionalen Einleitung zu seiner dreibändigen „Allgemeinen Geschichte des großen Bauernkrieges“ sein Geschichtsbild dar, wonach die Menschheit dem Ziel der Freiheit entgegensteuere und dass dieses nur durch eine „Taufe voll Blut" erreicht werden könne." Ähnlich argumentierte Friedrich Engels, ${ }^{12}$ der die materielle Geschichtsphilosophie weiter dachte und das zugespitzte

1 Jürgen Bücking, Der „Bauernkrieg“ in den habsburgischen Ländern als sozialer Systemkonflikt, 1524-1526, in: Geschichte und Gesellschaft (1975), Sonderheft 1, S. 168-192, hier S. 167-172.

2 Horst Buszello, Die Staatsvorstellung des "gemeinen Mannes“ im deutschen Bauernkrieg, in: Peter Blickle (Hrsg.), Revolte und Revolution in Europa. Referate und Protokolle des Internationalen Symposiums zur Erinnerung an den Bauernkrieg 1525 (Memmingen, 24.-27. März 1975) (= HZ Beiheft 4), S. 273-295.

$3 \quad$ Lebte von 1765 bis 1828.

4 Georg Friedrich Sartorius, Versuch einer Geschichte des deutschen Bauernkrieges oder der Empörung in Deutschland zu Anfang des sechszehnten Jahrhunderts, Berlin 1795.

5 Lebte von 1795 bis 1886.

6 Leopold von Ranke, Deutsche Geschichte im Zeitalter der Reformation, Berlin 1839, S. 210.

$7 \quad$ Ebd., S. 211-212.

8 Lebte von 1807 bis 1878

9 Lebte von 1797 bis 1845.

10 Ferdinand Friedrich Oechsle, Beiträge zur Geschichte des Bauernkrieges in den schwäbisch-fränkischen Grenzlanden, Heilbronn 1830, S. 153-174.

11 Wilhelm Zimmermann, Allgemeine Geschichte des deutschen Bauernkrieges, Bd. 1, Stuttgart 1842, S. 3-4.

12 Lebte von 1820 bis 1895. 
Konzept der "Revolution Nr. 1 der Bourgeoisie" entwarf, wobei die Reformation die Mittel für den „populären Ausdruck der allgemeinen Bestrebungen“ geliefert hätte. ${ }^{13}$

Ein zentrales Werk, das die Forschung der Jahrzehnte bis zum 450. Jubiläum des Bauernkrieges im Jahr 1975 maßgeblich beeinflusste, war die erstmals 1933 veröffentlichte und wiederholt neuaufgelegte Monographie "Der deutsche Bauernkrieg"14 von Günther Franz. ${ }^{15}$ Sie enthält eine detaillierte Schilderung des Verlaufs. Die Reformation tritt bei Franz als verursachender Faktor zurück, den Hauptgrund für die Aufstände will er in dem angespannten Verhältnis zwischen dem gemeindlich-genossenschaftlichen und dem territorialstaatlich-herrschaftlichen Prinzip gesehen haben. Später entstand im Jubiläumsjahr 1975 eine Flut neuer Publikationen, die den Einfluss der reformatorischen Bewegungen, die sich nicht nur auf Luther beschränken lassen, stärker hervorhob. ${ }^{16}$

Völlig unterschiedlich waren die Lehrmeinungen in der BRD und der DDR: In der DDR wurde auf Basis der Arbeiten Engels' das Konzept der "frühbürgerlichen Revolution“ entworfen, in dem Bauernkrieg und Reformation eng zusammengehörten. ${ }^{17}$ In der BRD wurde diese Theorie problematisiert, wobei dem Historiker Peter Blickle besondere Bedeutung zukommt. Er bemühte sich, durch gemeinsame Projekte mit Forscher*innen aus der DDR Gegenbegriffe zur "frühbürgerlichen Revolution" herauszuarbeiten. ${ }^{18}$ Mit dem Begriff der "Revolution des gemeinen Mannes" verwandte er einen zeitgenössischen Begriff, der neben Bauerntum auch die Bürger- und Knappschaft sowie Söldner*innen und den mediaten Adel einschließt. In den jüngeren Publikationen gilt dieser Begriff als allgemein anerkannt. ${ }^{19}$

Die vorliegende Arbeit ist so aufgebaut, dass zunächst nach Ursachen für den Ausbruch des Bauernkrieges auf allgemeiner Ebene gefragt wird; verschiedene Konfliktlinien sollen dabei aufgezeigt werden, ehe im zweiten Teil eine Auswahl verschiedener Aufstandsherde mit ihren lokalen Besonderheiten untersucht wird. Dabei will die Arbeit nicht den Anspruch einer genauen Chronologie der Ereignisse im gesamten Reich erheben, sondern anhand ausgewählter Beispiele regionale Spezifika herausarbeiten und in Beziehung zu den Entwicklungen auf Reichsebene setzen.

13 Friedrich Engels, Zum „Bauernkrieg”, in: Institut für Marxismus-Leninimus beim Zentralkomitee der SED (Hrsg.), Marx-Engels-Werke, Bd. 21, Berlin 1962, S. 402-404, hier S. 402-403.

14 Günther Franz, Der deutsche Bauernkrieg, Darmstadt 1984 ${ }^{12}$.

15 Lebte von 1902 bis 1992.

16 Peter Blickle, Die Revolution von 1525, München-Wien 1983², S. 191-195; Peter Blickle, Der Bauernkrieg. Die Revolution des Gemeinen Mannes (C. H. Beck Wissen 2103), München 1998, S. 244.

17 Max Steinmetz, Die dritte Etappe der frühbürgerlichen Revolution. Der deutsche Bauernkrieg 1524 bis 1526, in: Rainer Wohlfeil (Hrsg.), Der Bauernkrieg 1524-26. Bauernkrieg und Reformation (Nynmphenburger Texte zur Wissenschaft 21), München 1975, S. 65-89.

18 Michael Borgolte, Sozialgeschichte des Mittelalters. Eine Forschungsbilanz nach der deutschen Einheit, München 1996, S. 180

19 Günter Vogler, Revolte oder Revolution? Anmerkungen und Fragen zum Revolutionsproblem in der frühen Neuzeit, in: Stefan Ehrenpreis u. a. (Hrsg.), Wege der Neuzeit. Festschrift für Heinz Schilling zum 65. Geburtstag, Berlin 2007, S. 381-413, hier S. 398. 


\section{Ursachen}

Die Ursachen des Bauernkriegs waren vielfältig und sind deshalb nicht monokausal zu erklären. Es zeichnete sich in ganz Mitteleuropa ein umfassender Strukturwandel ab. Während Dörfer und Städte in jahrhundertelangen Verhandlungen, Aufständen und Kämpfen den Landesherr*innen immer mehr Rechte abringen konnten, verstärkte sich die Position der Landesherrinnen und Landesherren auf Reichsebene. Für die Grundproblematik des Bauernkrieges interessiert aber insbesondere das Verhältnis zwischen den sich zunehmend selbstverwaltenden Einheiten Stadt und Dorf und den ambitionierten Landesherrschaften. Diese wollten die Rechte der Bevölkerung beschneiden, u. a. durch die Entfremdung von Allmende-, Jagd- und Fischereirechten.

Mitverantwortlich für die spannungsgeladene Situation zwischen Landbevölkerung und Adel war die obsessive Jagdleidenschaft der Fürstinnen und Fürsten sowie die damit einhergehende Verwüstung mühsam bewirtschafteter Äcker und die Verpflichtung der Verpflegung der Jagdgesellschaft durch die Bauernschaft. ${ }^{20}$

Ein wichtiger Faktor war die Bildung urbaner Zentren im Spätmittelalter. Die Pestwelle von 1348/50 hatte kurzfristig fatale Folgen, langfristig kam es allerdings zur Vereinigung des Kapitals in den Händen weniger, was die Position des übriggebliebenen Bürgerstandes verstärkte. Die Leidtragenden dieser Entwicklung waren die Bäurinnen und Bauern: Durch den Anstieg der Preise für Gewerbeprodukte und die gleichzeitige Senkung der Lebensmittelpreise wurde eine Agrarkrise mit breiter Landflucht ausgelöst. ${ }^{21}$ Die Städte erlebten einen beträchtlichen Zuwachs und inkorporierten umliegende Dörfer und Weiler.

Die immer größer werdenden Städte entwickelten eine zunehmende Selbständigkeit in der politischen Landschaft des Reiches und wurden bald zu einem Störfaktor in den Augen der Landesherrschaften. Das aufstrebende städtische Bürgertum agierte äuBerst selbstbewusst und es schien nur noch eine Frage der Zeit zu sein, bis es politische Repräsentation auf noch breiterer Ebene einforderte.

Das Leben auf dem Land und in den weniger urbanisierten Gebieten gestaltete sich in vielen Belangen schwieriger. Das Herrschaftsrelief des Reiches war stark zerklüftet und nicht selten war eine Person mehreren Herrschaften untertan. Die Folgen waren deutlich höhere Abgaben.22 Auch die Dörfer strebten nach mehr Autonomie, doch dies wollten die Landesherr*innen wirksam verhindern. Aus einmaligen Abgaben, die in immer kürzeren Zeiträumen eingefordert wurden, erwuchsen regelmäßig zu entrichtende Steuern, die einen wesentlichen Teil des "Staatshaushalts" ausmachten. Ein weiteres Mittel der Besteuerung war das Einziehen der sich im Umlauf befindlichen Münzen und deren Ausgabe unter einem geringeren Edelmetallgehalt - der Entwer-

20 Rudolf Endres, Franken, in: Peter Blickle/Horst Buszello/Rudolf Endres (Hrsg.), Der deutsche Bauernkrieg, München u. a. 1995³, S. 134-153, hier S. 137.

21 Horst Buszello, "Wohlfeile“ und „Teuerung" am Oberrhein 1340-1525 im Spiegel zeitgenössischer erzählender Quellen, in: Peter Blickle (Hrsg.), Bauer, Reich und Reformation. Festschrift für Günther Franz zum 80. Geburtstag am 23. Mai 1982, Stuttgart 1982, S. 18-42, hier S. 19-20. 
tungsprozess des Geldes schritt dadurch kontinuierlich voran, während Löhne und Preise auf dem gleichen Niveau blieben. ${ }^{23}$

Während der Agrarkrise waren die Bauernstände oftmals nicht mehr in der Lage, ihre Abgaben zu leisten, sodass die Herrschenden die sog. „Blutzapfen“, bewaffnete Söldner*innen, in die Dörfer schickten, um die Steuern gewaltsam einzutreiben. Dazu kamen Überschwemmungen, Dürreperioden und Lawinenabgänge, die der Landwirtschaft schadeten. Die noch kaum regulierten Flussläufe waren von krankheitsverursachenden Sümpfen und Auenlandschaften umgeben. ${ }^{24}$

Wer seine Schulden nicht begleichen konnte, flüchtete in die Städte und überließ der restlichen Gemeinde die Zahlung offener Beiträge, was zu einem Klima des Misstrauens und der Denunziation führte. Dem Zugriff des ohnehin wirtschaftlich schwachen Adels wurden also immer mehr Produktionskräfte entzogen - die verstärkte Reaktivierung der Leibeigenschaft sollte die Landflucht eindämmen und die Territorien nach außen hin festigen. Durch das Verbot der "ungenoßsamen Ehe", d. h. der Ehe zwischen zwei Personen, die unterschiedlichen Herrinnen und Herren unterstanden, sollten die Bauern- und Bäuerinnenfamilien an ihren Hof gebunden werden: Es ging also um die Immobilisierung der Landbevölkerung. ${ }^{25}$

Im gesamten Reich zeichnete sich dieser Territorialisierungsprozess ab, der eine große Reorganisierung mit sich brachte. Der Begriff der Herrschaftsverdichtung

„steht für ein ganzes Wortfeld, das die zentrierende und komprimierende Bewegung auf eine Mitte hin im Gegensatz zu zentrifugalen und auflockernden Bewegungskräften zum Ausdruck bringt. Dieses Wortfeld umfaßt Begriffe wie Zusammenfassung, Verflechtung, Konzentration, Reduktion, Intensivierung, Anspannung, Durchdringung, Normierung, Regulierung, Einbindung, Vereinheitlichung und Vereinfachung [...]."26

Die Territorialisierung konnte von der Grundherrschaft oder von der Leibherrschaft ausgehen. Da alle Grundherrschaften dieselben Interessen hatten, war es nicht schwierig, ganze Landstriche zu verkaufen und von dem dadurch erhaltenen Geld ein neues, näher gelegenes Gebiet zu erwerben. Bei der Leibherrschaft gestaltete sich die Territorialisierung wesentlich komplizierter: Zunächst wurden einzelne Personen und Familien umgesiedelt, doch schon bald wurde der Übergang in eine andere Leibherrschaft rationalisiert - es gab Fälle, in denen mehr als tausend Personen ihre Herrschaften wechselten. Sie konnten aber weiterhin auf dem Hof bleiben, den sie bis zu diesem Zeitpunkt bewirtschaftet hatten. ${ }^{27}$

23 Rudolf Endres, Ursachen, in: Blickle/Buszello/Endres (Hrsg.), Der deutsche Bauernkrieg, S. 217-253, hier S. 240.

24 Eine ausführliche Darstellung der dokumentierten Naturkatastrophen für den Zeitraum 1340-1525 ist angeführt bei: Buszello, "Wohlfeile" und "Teuerung" am Oberrhein, S. 30-42.

25 Endres, Ursachen, S. 236-237.

26 Berndt Hamm, Das Gewicht von Religion, Glaube, Frömmigkeit und Theologie innerhalb derVerdichtungsvorgänge des ausgehenden Mittelalters und der frühen Neuzeit, in: Monika Hagenmaier/Sabine Holtz (Hrsg.), Krisenbewußtsein und Krisenbewältigung in der frühen Neuzeit - Crisis in early modern Europe. Festschrift für Hans-Christoph Rublack, Frankfurt am Main u. a. 1992, S. 163-196, hier S. 164. 
Es war nicht nur Ziel des Adels, seine „zufällig zusammengeerbten und zusammengekämpften"28 Gebiete zu einem einheitlichen Territorium zusammenzufassen: Auch die bäuerliche Landbevölkerung wollte nur einem Herren oder einer Herrin unterstehen. Doch während der Adel Entscheidungsgewalt über innerdörfliche Angelegenheiten beanspruchte, verstanden der gemeine Mann und die gemeine Frau das Dorf als eigenständigen politischen Körper, in dem die Besetzung des Bürgermeisteramtes nach dem Prinzip der Wahl bestimmt wurde und diese Person auch in der Rechtsprechung autonom agieren konnte. Die Landesherrschaft hingegen bemühte sich um die kapillare Beherrschung der Gebiete. Je kürzer nämlich die Entfernung zwischen den Bauern- und Bäuerinnenfamilien und ihrer Herrschaft war, desto leichter war die Untertanenschaft verwaltungstechnisch zu erfassen und zu beherrschen. ${ }^{29}$ Wesentlichen Anteil daran hatte der Aufbau einer breiten Beamtenschaft, die den Zugriff des Adels auf innerdörfliche Angelegenheiten sicherte. Besonders jene Personen im öffentlichen Dienst, die vielfach in die eigenen Taschen wirtschafteten, waren Gegenstand des Missmutes der Bauernschaft. Zudem erfuhr das römische Recht eine Welle breiter Rezeption bei den Landesherr*innen, da es den Dschungel der verschiedenen Rechtsordnungen vereinheitlichen konnte und für die großräumige Verwaltung eines Gebietes ein wichtiges Werkzeug war. Dadurch wurden viele bestehende genossenschaftliche Rechte vollständig außer Kraft gesetzt. ${ }^{30}$ Günther Franz sieht gerade in diesem "Antagonismus zwischen herrschaftlichem und genossenschaftlichem Prinzip"31 den Hauptgrund für den Ausbruch des Bauernkrieges.

Nach der Pestwelle 1348/50 stieg die Bevölkerung rasant an. Aus den Untertanenverzeichnissen des oberschwäbischen Ottobeuer lässt sich beispielsweise herauslesen, dass die Höfe im Jahr 1548 durchschnittlich 18,42 Prozent mehr Menschen ernähren und unterbringen mussten als dies 1450 der Fall gewesen war. ${ }^{32}$ Äußerst dramatisch war zudem für viele das Phänomen der Hofteilung: Während der älteste Sohn den gesamten Hof erbte, mussten seine Geschwister meistens als Tagelöhner, Knechte und Mägde ein Auskommen finden, wobei sie oft in die Leibeigenschaft hinabsanken. Einige entschieden sich für den Eintritt in eine Söldnerarmee. Viele endeten als Bettler*innen auf der Straße oder lebten von Raubüberfällen auf vorbeiziehende Händlerinnen und Händler oder nahegelegene Höfe. ${ }^{33}$

Die städtischen Bürgerfamilien wollten ihre mühsam errungene Position sichern und sahen sich von dem umherziehenden „Heer von Bettlern“34 bedrängt, sodass sie restriktive Armenordnungen und sogar Bettelverbote erließen: Die Zahl der Wachposten an den Stadttoren wurde vielerorts erhöht, in der Stadt aufgegriffene, landlose

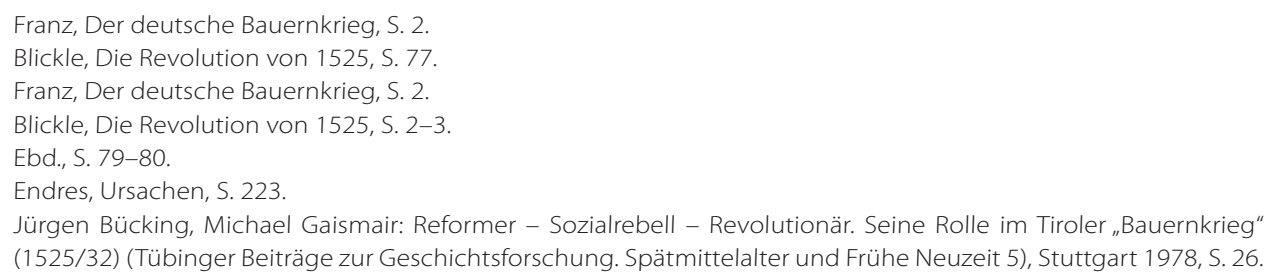


Bettler*innen wurden sofort verwiesen und nicht selten kam es dabei zur Anwendung von Gewalt. ${ }^{35}$

Dieses Bündel von Faktoren schuf im gesamten Reich eine spannungsgeladene Situation, die jederzeit eskalieren konnte. Viele Historiker*innen sprechen von einem „politisch-gesellschaftlichen Systemkonflikt",36 der den Übergang vom Gesellschaftssystem des Feudalismus in jenes des Kapitalismus markierte - jedenfalls in den Augen vieler Geschichtsforschenden der DDR. Heute gilt diese Betrachtungsweise als überholt. Es stellt sich allgemein die problematische Frage, ob der Bauernkrieg noch dem Mittelalter oder bereits der Neuzeit zuzuordnen sei. ${ }^{37}$ Diese Frage hängt unmittelbar damit zusammen, welche Periodisierung verwendet wird. Der Bauernkrieg bewegt sich entlang einer Vielzahl typisch spätmittelalterlicher Konfliktlinien und lässt sich ohne den Hinweis auf die unten beschriebenen Aufstände der Bäuerinnen und Bauern seit dem 13. Jahrhundert nur unzulänglich erklären. Das grundlegend Neue war hingegen die Verbindung des Bauernkriegs mit der in vielen Aufstandsgebieten sich ausbreitenden Reformation. So gesehen ist der Bauernkrieg also in die Tradition der spätmittelalterlichen Bauern- und Bäuerinnenaufstände einzuordnen, wobei er durch das Hinzutreten der Reformation eine neue Qualität gewann und systemsprengenden Charakter erhielt. Für die Ursachenfrage hingegen kann die Reformation nicht hinzugezogen werden - eher kam ihr die „Funktion eines Auslösers oder Katalysators“38 zu, die den Aufständischen neue Argumente für die Bekämpfung alter Probleme lieferte.

Verschiedene Geschichtsschreiber*innen haben den Bauernkrieg als „missverstandene Reformation"39 bezeichnet, doch diese Interpretation lässt sich nicht länger halten, wenn der Terminus „Reformation“ überdacht wird. Damit soll nicht nur die Glaubenslehre Luthers gemeint sein; der Begriff umfasst auch die Exponenten des sogenannten „linken Flügels der Reformation"40 oder der "radikalen Reformation".41 Damit sind Thomas Müntzer, Andreas Bodenstein, Kaspar Schwenckfeld, Huldrich Zwingli sowie die Männer und Frauen der Täufer*innen, der Antitrinitarier*innen und der Spiritualist*innen gemeint. ${ }^{42}$

Der von Luther in der 1520 veröffentlichten Denkschrift "Von der Freiheit eines Christenmenschen" erwähnte Begriff der Freiheit hatte eine ungeahnte Wirkung. Das Konzept der lutherischen Freiheit war nicht auf die politische, sondern ausschließlich auf die religiöse Welt bezogen - die Prädikanten und Prädikantinnen, welche die Ideen Luthers auf das Land hinaustrugen, gaben allerdings eigene Interpretationen hinzu, sodass der Freiheitsbegriff beim Stand der Bäuerinnen und Bauern auf die politischgesellschaftliche Ordnung übertragen wurde.

35 Endres, Ursachen, S. 221

36 Rainer Wohlfeil, Nachwort, in: Wohlfeil (Hrsg.), Der Bauernkrieg 1524-26, S. 280-282, hier S. 280.

37 Richard van Dülmen, Reformation als Revolution. Soziale Bewegung und religiöser Radikalismus in der deutschen Reformation, München 1977, S. 42.

38 Endres, Ursachen, S. 217

39 Blickle, Die Revolution von 1525, S. 244.

40 Heinold Fast (Hrsg.), Der linke Flügel der Reformation. Glaubenszeugnisse der Täufer, Spiritualisten, Schwärmer und Antitrinitarier (Klassiker des Protestantismus 4, Sammlung Dieterich 269), Bremen 1962.

41 Blickle, Die Revolution von 1525, S. 244.

42 George Huntston Williams, The Radical Reformation. Sixteenth Century Essays and Studies, Kirksville 1992. 


\section{Bauern- und Bäuerinnenaufstände im Spätmittelalter}

\subsection{Die Entstehung der Schweizer Eidgenossenschaft}

Die Entstehung der Eidgenossenschaft ist ein frühes Beispiel für die Durchsetzung des genossenschaftlich-ständischen Prinzips gegenüber dem herrschaftlichen. Nachdem das Geschlecht der Zähringer, das seit dem Ende des 11. Jahrhunderts weite Teile der heutigen Schweiz beherrschte, ausgestorben war, ${ }^{43}$ wurden Zürich, Bern und Freiburg zu Reichsstädten, Uri und Schwyz wurden 1231 und 1240 sogar zu reichsunmittelbaren, also direkt dem Kaiser unterstehenden Gebieten. Kaiser Friedrich II. stellte ihnen diese Privilegien aus, um sich ihre Unterstützung gegen lokale Fürstentümer zu sichern, die sich mit dem Lombardischen Städtebund zusammengeschlossen hatten und ihn an der Überquerung des Gotthardpasses hindern wollten. ${ }^{44}$

1273 wurde mit Rudolf I. von Habsburg ein aus den Gebieten der heutigen Schweiz stammender Fürst zum Kaiser erwählt. Er setzte eine Reihe von Vögt*innen ein, die als Gegner*innen zu den lokalen Adelsgewalten auftraten. Aus der Zeit unmittelbar nach dem Tod Rudolfs im Jahr 1291 datiert ein erster Bundesbrief, in dem die drei Urkantone Uri, Schwyz und Unterwalden bekräftigten, die seit der Regierungszeit Friedrichs II. eingeräumten Rechte weiterhin verteidigen zu wollen. 1309 erhielt auch Unterwalden von Kaiser Heinrich VII. das Privileg der Reichsunmittelbarkeit. In den Kriegen der folgenden zwei Jahrhunderte erweiterte sich das Gebiet der Schweizer Eidgenossenschaft sukzessive. ${ }^{45}$

In den späteren Aufständen sowie im Bauernkrieg erlebte die Rezeption der Eidgenossenschaft eine Hochkonjunktur, da sie als Vorreiter im Kampf für genossenschaftliche Rechte galt. Viele wollten „frei sein wie die Schweizer“.46

\subsection{Die Bundschuh-Bewegung}

Die Bundschuh-Bewegung war von einer Reihe einzelner Aufstände in südwestdeutschen Gebieten zwischen 1476 und 1517 gekennzeichnet. Der Begriff leitet sich von den bäuerlichen Feldzeichen ab, auf denen das Motiv des gebundenen Lederschuhs abgebildet war. Damit sollte in Abgrenzung zu den ritterlichen Reiterstiefeln die Kluft zwischen dem Stand der Bauern und Bäuerinnen und dem Adel aufgezeigt werden. ${ }^{47}$

Den Beginn des Bundschuhs markierte die Tätigkeit des Predigers Hans Böhm, ${ }^{48}$ auch „Paukervon Niklashausen"49 genannt. Höchstwahrscheinlich waren seine Vorfahr*innen,

43 Guy Paul Marchal, Die Ursprünge der Unabhängigkeit, in: Beatrix Mesmer (Hrsg.), Geschichte der Schweiz und der Schweizer, Basel 20064 , S. 109-214, hier S. 136-139.

44 Ebd., S. 165-212.

45 Bernhard Stettler, Die Eidgenossenschaft im 15. Jahrhundert. Die Suche nach einem gemeinsamen Nenner, Zürich 2004.

46 Horst Buszello, Der deutsche Bauernkrieg von 1525 als politische Bewegung. Mit besonderer Berücksichtigung der anonymen Flugschrift An die Versamlung Gemayner Pawerschafft, Berlin 1969, S. 85.

47 Willy Andreas, Deutschland vor der Reformation. Eine Zeitenwende, Stuttgart 19596, S. 439.

48 Lebte etwa von 1458 bis 1476.

49 Otto Graf zu Stolberg-Wernigerode, Böhm (Beheme), Hans (Pauker von Niklashausen, Pfeiferhänsle), in: Neue Deutsche Biographie, Bd. 2, Berlin 1955, S. 382. 
die während der Hussitenkriege nach Franken gekommen waren, aus Böhmen eingewandert. Schon früh wurde Böhm zum Waisen und musste sich seinen Lebensunterhalt auf eigene Faust verdienen - als Viehhirte sah er sich mit einer Reihe von Ungerechtigkeiten konfrontiert. ${ }^{50}$ Nachdem er eine Marienerscheinung erlebt haben will, trat er während der Fastenzeit 1476 als Prediger auf und rief zu einer Marienwallfahrt nach Niklashausen auf. Böhms Predigten nahmen bestimmte Forderungen der Bauernschaft vorweg, welche diese knapp fünfzig Jahre später an ihre Herrschaften richteten. Er bewog die ihm zuhörende Menge dazu, ihre Wertgegenstände symbolisch auf dem Scheiterhaufen zu verbrennen. Darüber hinaus prangerte er den Reichtum und die Habsucht des Adels und der Kirche sowie die Anhäufung von Pfründen an, verwarf das Konzept des Fegefeuers und des Ablasshandels, kritisierte die hohen Abgaben und forderte die Rückgabe der Allmende. ${ }^{51}$

Anfangs hatten sowohl der Mainzer Erzbischof Diether von Isenburg ${ }^{52}$ als auch der Würzburger Fürstbischof Rudolf II. von Scherenburg ${ }^{53}$ nichts gegen die von Böhm initiierte Wallfahrt einzuwenden. Doch als dieser 40.000 Anhänger*innen hinter sich scharte, waren sie alarmiert und verboten die Wallfahrt. Böhm wurde gefangen genommen und einem Verhör über die Quellen seiner Ideen unterzogen. Dabei hatte er als Waise nur verschiedene Meinungen auf der Straße aufgegriffen und war sich der Sprengkraft seiner Rede als Achtzehnjähriger kaum bewusst. Er schien Analphabet gewesen zu sein, der über keinerlei Lateinkenntnisse verfügte. Am 19. Juli wurde Böhm in Würzburg auf dem Scheiterhaufen verbrannt und seine Asche in den Main gestreut. Das Spielen seiner Lieder wurde streng sanktioniert und das Kirchlein in Niklashausen auf Befehl Diethers von Isenburg abgerissen..$^{54}$

Im elsässischen Schlettstadt richtete sich der Protest gegen die hohe Steuerbelastung. Die Wut der Bevölkerung zielte nicht nur gegen die weltliche und geistliche Obrigkeit, sondern auch gegen Jüdinnen und Juden. ${ }^{55}$ Ähnlich wie später die „Pfaffen“ kamen sie aus der Stadt und galten der ländlichen Bevölkerung als Fremdkörper. Die Führungsriege kam vermehrt aus bürgerlichen Kreisen, z. B. der ehemalige Bürgermeister Johann Ullmann ${ }^{56}$ und der Schultheiß von Blienschweiler, Jakob Hanser - beide wurden hingerichtet, Ersterer durch Vierteilung..$^{57}$

50 Klaus Arnold, Niklashausen 1476. Quellen und Untersuchungen zur sozialreligiösen Bewegung des Hans Behem und zur Agrarstruktur eines spätmittelalterlichen Dorfes, in: Mainfränkisches Jahrbuch für Geschichte und Kunst 36 (1984), S. 326-332, hier S. 327.

51 Franz, Der deutsche Bauernkrieg, S. 49-50.

52 Lebte etwa von 1412 bis 1482. Ernst Bock, Dieter Graf von Isenburg, in: Neue Deutsche Biographie, Bd. 3, Berlin 1957, S. 668-669.

53 Lebte etwa von 1401 bis 1495. Helmut Flachenecker, Rudolf II. von Scherenberg, in: Neue Deutsche Biographie, Bd. 22, Berlin 2005, S. 192-193.

54 Klaus Arnold, Neues zu Niklashausen 1476, in: Franklin Kopitzsch/Rainer Postel (Hrsg.), Reformation und Revolution. Beiträge zum politischen Wandel und den sozialen Kräften am Beginn der Neuzeit. Festschrift für Rainer Wohlfeil zum 60. Geburtstag, Stuttgart 1989, S. 69-89, hier S. 69-73.

55 Franz, Der deutsche Bauernkrieg, S. 56-62.

56 Starb 1493.

57 Andreas, Deutschland vor der Reformation, S. 443. 
Im zum Bistum Speyer gehörigen Untergrombach kam es in den Jahren 1501/02 zu Aufständen, nachdem im Sommer eine Pest- und Hungerwelle über das Gebiet hinweggezogen war. Anführer war der ehemalige Söldner Joß Fritz, der als Sohn von Leibeigenen selbst das Unrecht erfahren hatte, das viele mit ihm teilten. Er forderte eine Vermögensverteilung und die totale politische Entrechtung des Adels; lediglich Kaiser und Papst sollten als Obrigkeit anerkannt werden. Über 7.000 Anhänger*innen konnte er hinter sich scharen, ehe der Aufstand durch den Hinweis des Söldners Lukas Rapp bei einem Beichtvater entlarvt und von den bischöflichen Truppen niedergeschlagen wurde. ${ }^{58}$ Während über hundert Anführer*innen hingerichtet wurden, gelang Joß Fritz die Flucht. 1513 brach er in Lehen in Breisgau mit denselben Forderungen einen neuen Aufstand vom Zaun, der ebenfalls wirkungslos verpuffte. ${ }^{59}$

\subsection{Der Arme Konrad}

Der Arme Konrad bezeichnet einen Aufstand großer Teile der Bauern- sowie Bauernund Bürgerschaft gegen Herzog Ulrich von Württemberg (1487-1550) ${ }^{60}$ im Jahr 1514, der durch die Einführung des römischen Rechts und die Durchdringung der Verwaltung durch habgieriges Beamtentum im Zuge der "Herrschaftsverdichtung" großen Unmut erregt hatte. ${ }^{61}$ Nachdem es zu Missernten und extremen Preissteigerungen gekommen war - der Preis für einen Scheffel Dinkel stieg innerhalb kürzester Zeit beinahe um das Sechsfache ${ }^{62}$-, führten die versammelte Bürger- und Bauernschaft eine Steinprobe durch: Sie warfen die neu festgelegten Gewichte in die Rems und weil diese auf den Grund des Flusses sanken, interpretierten sie das Gottesurteil zu ihren Gunsten und bezeichneten die Maßnahmen des Herzogs als unrecht.63 Interessant ist, dass sich die Bürgervertretung genau derselben juristischen Mittel bediente, die gegen viele aus ihren eigenen Reihen im Rahmen von Hexerei- und Ketzereiprozessen zur Anwendung kamen.

58 Thomas Adam, Joß Fritz - das verborgene Feuer der Revolution. Bundschuhbewegung und Bauernkrieg am Oberrhein im frühen 16. Jahrhundert (Veröffentlichungen der Historischen Kommission der Stadt Bruchsal 20), Ubstadt-Weiher 2002, S. 80-132.

59 Ebd., S. 133-210.

60 Gabriele Haug-Moritz, Ulrich I., Herzog von Württemberg, in: Neue Deutsche Biographie, Bd. 26, Berlin 2016, S. 600-601.

61 Georg Moritz Wendt, Der Fehler im System. Der "Arme Konrad“ im Kontext der württembergischen Herrschaftsverdichtung, in: Sigrid Hirbodian/Robert Kretzschmar/Anton Schindling (Hrsg.), "Armer Konrad” und Tübinger Vertrag im interregionalen Vergleich. Fürst, Funktionseliten und „Gemeiner Mann“ am Beginn der Neuzeit (Veröffentlichungen der Kommission für geschichtliche Landeskunde in Baden-Württemberg, B/206), Stuttgart 2016, S. 325-342, hier S. 325-334.

62 Andreas Schmauder, Württemberg im Aufstand. Der Arme Konrad 1514. Ein Beitrag zum bäuerlichen und städtischen Widerstand im Alten Reich und zum Territorialisierungsprozeß im Herzogtum Württemberg an der Wende zur frühen Neuzeit (Schriften zur südwestdeutschen Landeskunde 21), Leinfelden-Echterdingen 1998, S. 39-44.

63 Hans-Martin Maurer, Der Arme Konrad als Schlüsselereignis württembergischer Geschichte, in: Uwe Jens Wandel (Hrsg.), Der Arme Konrad. Die Vorträge und Referate des Schorndorfer Symposions 1986, Schorndorf 1991, S. 8-25, hier S. 12-15. 
Intellektueller Anführer der Bewegung war der Tübinger Universitätsdozent Reinhard Gaißer. ${ }^{64}$ Nachdem es in verschiedenen benachbarten Städten zu Protesten gekommen war, sah sich Herzog Ulrich gezwungen, dem Aufstand der Bäuerinnen und Bauern entgegenzukommen. Auf dem von ihm einberufenen Landtag wurde der Tübinger Vertrag ${ }^{65}$ unterschrieben, der den Untertan*innen Mitspracherechte bei den Ausgaben sowie die freie Wahl des Wohnortes einräumte. ${ }^{66}$ Im Gegenzug mussten die Aufständischen akzeptieren, dass Landfriedensbruch mit der Todesstrafe bestraft werden sollte. Durch diesen geschickten Zusatz konnte der Herzog den Aufstand problemlos niederschlagen: Über 1.700 Aufständische sollen gefangen genommen worden sein, viele von ihnen wurden der Folter unterzogen, mit heißen Eisen gebrandmarkt und die Führungsriege in Schauprozessen hingerichtet. ${ }^{67}$

Insgesamt konnten alle Aufstände, seien es jene der Bundschuh-Bewegung wie auch jene des Armen Konrads, von lokalen Gewalten niedergeschlagen werden, was die Verbitterung und das Konfliktpotenzial noch stärker auflud. Diese im Untergrund brodelnde Opposition gegen die bestehende Obrigkeit war ausschlaggebend für die über die Landesgrenzen hinwegreichende mobilisierende Wirkung der verschiedenen regionalen Aufstände im Bauernkrieg von 1524 bis $1526 .{ }^{68}$

\section{Vier Aufstandherde des Bauernkrieges und ihre (verfassungstheoretischen) Spezifika}

\subsection{Oberrhein: Die Ausweitung lokaler Erhebungen zum Bauernkrieg}

Nachdem die Stühlinger Bauernschaft seit dem 23. Juni 1524 Proteste gegen ihren Landgrafen Sigmund von Lupfen initiiert hatte, sah sich Erzherzog Ferdinand ${ }^{69}$ gezwungen, in den Tiengener Verhandlungen einem Waffenstillstand bis zum 24. August zuzustimmen. Währenddessen begannen sich die landwirtschaftlichen Stände

64 Lebte etwa von 1474 bis 1533. Zu seiner Person siehe: Robert Kretzschmar, Waß ich thu, das handel ich uß des dectors kopf und rath. Zur Rolle des Markgröninger Pfarrers Dr. Reinhard Gaißlin im „Armen Konrad”. Mit einer Edition der Berichte des Vogts Philipp Volland, in: Hirbodian/Kretzschmar/Schindling (Hrsg.), Armer Konrad“ und Tübinger Vertrag im interregionalen Vergleich, S. 63-96.

65 Transkription des Vertragstextes bei: Eugen Schneider (Hrsg.), Ausgewählte Urkunden zur Württembergischen Geschichte (Württembergische Geschichtsquellen 11), Stuttgart 1911, S. 87-93.

66 Robert Kretzschmar/Peter Rückert, Der "Arme Konrad” in Württemberg 1514. Selbstverständnis, Artikulation und Kommunikation, in: Hirbodian/Kretzschmar/Schindling (Hrsg.), "Armer Konrad" und Tübinger Vertrag im interregionalen Vergleich, S. 33-62, hier S. 36-40.

67 Hermann Römer, Die Anfänge Herzog Ulrichs und der Aufstand des Armen Konrad in Markgröningen, in: Hermann Römer (Hrsg.), Markgröningen im Rahmen der Landesgeschichte, Bd. 1, Markgröningen 1933, S. 190-229.

68 Adolf Laube, Die Volksbewegung in Deutschland von 1470 bis 1517 . Ursachen und Charakter, in: Peter Blickle (Hrsg.), Revolte und Revolution in Europa, S. 84-98, hier S. 97-98.

69 Ferdinand I. (1503-1564) aus dem Haus der Habsburger war von 1521 bis zu seinem Tod Erzherzog von Österreich, von 1526 bis 1562 König von Böhmen, von 1526 bis 1563 König von Ungarn, von 1527 bis 1563 König von Kroatien und Slawonien und von 1558 bis zu seinem Tod Kaiser des Heiligen Römischen Reichs. Der Sohn Philipps I. stand lange im Schatten seines Bruders, der als Karl I. von 1519 bis 1521 Erzherzog von Österreich und als Karl V. von 1519 bis 1556 Kaiser war. Für den Bauernkrieg spielte er insofern eine große Rolle, als er die Herrschaft über die nach den vielen Kriegen aus der Zeit seines Großvaters Maximilian I. wirtschaftlich zerrüttete Gefürstete Grafschaft Tirol übernahm. Zur Person Ferdinands siehe: Adam Wandruszka, Ferdinand I., in: Neue Deutsche Biographie, Bd. 5, Berlin 1961, S. 81-83. 
zu organisieren und erwählten Hans Müller von Bulgenbach ${ }^{70}$ zu ihrem Hauptmann. Nach dem Waffenstillstand zogen 800 Bäuerinnen und Bauern nach Waldshut, wo der reformatorische Prediger Balthasar Hubmaier ${ }^{71}$ einen seit Dezember 1523 laufenden Aufstand gegen den Erzherzog anführte. Zu differenzieren ist die Zielsetzung der verschiedenen Gruppen: Während die Stühlinger Bauerneineheiten ihre Situation durch die Berufung auf das „Alte Recht" und auf Herkommen verbessern wollten, kam bei den Waldshuter*innen der religiöse Aspekt hinzu. ${ }^{72}$

Am 2. Oktober schlossen sich die Hegauer und am 1. November die Bauernfration des Kloster St. Blasien in der Grafschaft Hauenstein dem Aufstand an. Im Klettgau wurde eine Beschwerdeschrift verfasst, in der bereits auf das "göttliche Recht" Bezug genommen wurde. Schnell entwickelten die Ereignisse eine solche Dynamik, dass sich die Obrigkeiten gezwungen sahen, der Forderung nach Verhandlungen nachzugeben. Da viele Truppen aufgrund der Feldzüge Kaiser Karls V. gegen den französischen König Franz I. in Italien gebunden waren, war die Einigung auf den Verhandlungsweg eine Möglichkeit, um Zeit zu gewinnen und die Gruppen der Bäuerinnen und Bauern zu einem späteren Zeitpunkt niederzuschlagen oder zum Auseinanderlaufen zu bewegen. ${ }^{73}$

Nachdem Herzog Ulrich von Württemberg wegen der Unterstützung der Bauerneinheiten im Armen Konrad aus seinem Territorium vertrieben wurde und sich aus politischen Gründen der Reformation anschloss, fühlte er sich bereit, mit dem französischen König auf seiner Seite die Rückeroberung zu versuchen. Doch nachdem dieser in der Schlacht von Pavia am 24. Februar 1525 vom Kaiser in Gefangenschaft genommen wurde, waren die kaiserlichen Truppen für eine Intervention am Oberrhein frei geworden und Herzog Ulrich brach seinen Rückeroberungsversuch ab. ${ }^{74}$ Dies hatte insofern eine große Auswirkung auf den Bauernkrieg, als der Schwäbische Bund ${ }^{75}$ sich massiv auf einen Feldzug gegen den Herzog vorbereitet hatte und die ganze Truppenstärke nun gegen die aufständischen Bauerneinheiten einsetzen konnte. ${ }^{76}$

Die Stühlinger Bauernschaft organisierten sich militärisch in einem Haufen, einen militärisch-politischen „,Kampfbund' zur Errichtung einer neuen, wahr-haft christlichen Volksgemeinschaft".77 Sie schafften es, am 24. Mai Freiburg einzuneh-men. Doch die Aufstände rund um die Stadt fielen einer nach dem anderen in sich zusammen - so

70 Lebte von1485/95 bis 1525. Horst Buszello, Müller (genannt von Bulgenbach), Hans, in: Neue Deutsche Biographie, Bd. 18, Berlin 1997, S. 397-398.

71 Lebte etwa von 1485 bis 1528. Bernd Moeller, Hubmaier, Balthasar, in: Neue Deutsche Biographie, Bd. 9, Berlin 1972, S. 703.

72 Horst Buszello, Oberrheinlande, in: Blickle/Buszello/Endres (Hrsg.), Der deutsche Bauernkrieg, S. 61-96, hier S. 6365 .

73 Ebd., S. 63-71.

74 Ebd., S. 73 .

75 Der Schwäbische Bund wurde 1488 auf Betreiben Kaiser Friedrichs III. zum Zweck der Erhaltung des reichsweiten Landfriedens gegründet. Erwurde er unterVorsitz Georgs III. Truchseß von Waldburg-Zeil gegen die aufständischen Bauern eingesetzt. Siehe dazu: Horst Carl, Der Schwäbische Bund 1488-1534. Landfrieden und Genossenschaft im Übergang vom Spätmittelalter zur Reformation (Schriften zur südwestdeutschen Landeskunde 24), LeinfeldenEchterdingen 2000.

76 Franz, Der deutsche Bauernkrieg, S. 106-107.

77 Buszello, Oberrheinlande, S. 74. 
auch jene in Radolfzell nach der erfolglosen Belagerung der Stadt und im Hegau, wo die Bauerngruppierungen die vom Schwäbischen Bund diktierten Kapitulationsbedingungen ${ }^{78}$ akzeptieren mussten. Hans Müller wurde von der Österreichischen eamtenschaft aufgespürt und am 12. August enthauptet. ${ }^{79}$ Einen friedlicheren Ausgang gab es in der Ortenau, wo am 25. Mai auf Basis der Zwölf Artikel der in der oberschwäbischen Reichsstadt Memmingen versammelten Bauernvertretung ein Vertrag zwischen Bauerncliquen und Obrigkeiten ausgehandelt wurde. ${ }^{80}$ Waldshut sah sich am 5. Dezember zur Kapitulation gezwungen. Hubmaier gelang die Flucht, ehe er Jahre später im mährischen Nikolsburg, wo er sich den Täufer*innen angeschlossen hatte, aufgespürt wurde und am 10. März 1528 in Wien auf dem Scheiterhaufen sein Ende fand. ${ }^{81}$

Auch im Elsass bildeten die Zwölf Artikel die Grundlage der bäuerlichen Forderungen. Sie wirkten über ihr Entstehungsgebiet hinaus als Programmschrift, die dazu beitrug, eine Verbindung zwischen den einzelnen Aufständen zu schaffen. Der elsässische Führer der Bäuerinnen und Bauern, Erasmus Gerber, ${ }^{82}$ legte fest, dass jede Gemeinde ein Viertel der männlichen Bevölkerung im wehrfähigen Alter für jeweils acht Tage zum Haufen schicken sollte, während die anderen zu Hause blieben, um die Felder zu bestellen. Mit dieser wohldurchdachten Strategie stellte er ein Gleichgewicht zwischen militärischer Präsenz und Aufrechterhaltung der bäuerlichen Wirtschaft her. Am 11. Mai schlossen sich die 13 elsässischen Haufen zusammen, ${ }^{83}$ doch ihr Erfolg war nicht von langer Dauer: Am 19. Mai fiel Herzog Anton II. von Lothringen ${ }^{84}$ ins Elsass ein. Die Aufständischen wurden regelrecht niedergemetzelt, deren Frauen von den Söldnern vergewaltigt - die Bilanz waren ungefähr 18.000 Tote. $^{85}$

\subsection{Oberschwaben: Der Versuch einer gemäßigten Reform und die Zwölf Artikel als integrative Programmschrift}

Oberschwaben war ein Raum mit einer stark zerklüfteten politischen Landschaft, in der nicht selten eine Bauernschaft mehreren Herrschaften gleichzeitig unterstand. ${ }^{86}$ Im Allgäu hatten die Fürstäbte und -äbtissinnen von Kempten schon im 15. Jahrhundert im Rahmen der Territorialisierung die persönlichen Abhängigkeitsverhältnisse verstärkt. Die Bauernstände, die aus Protest die Grafen von Montfort zu ihrer Schirmherrschft wählten und den Kaiser um Hilfe baten, wurden 1423 durch einen gefälschten Stiftsbrief des

78 Abdruck der Hegauer Artikel in: Günther Franz (Hrsg.), Quellen zur Geschichte des Bauernkrieges (Ausgewählte Quellen zur deutschen Geschichte der Neuzeit. Freiherr vom Stein-Gedächtnisausgabe 2), Darmstadt 1963, S. 578-579.

79 Buszello, Oberrheinlande, S. 74-77.

80 Ebd., S. 78-79.

81 Ebd., S. 79.

82 Gestorben 1525. Günther Franz, Gerber, Erasmus, in: Neue Deutsche Biographie, Bd. 6, Berlin 1964, S. $254-255$.

83 Buszello, Oberrheinlande, S. 87-88.

84 Lebte von 1489 bis 1544. Otto Graf von Looz-Corswarem, Anton der Gute, in: Neue Deutsche Biographie, Bd. 1, Berlin 1952, S. 316.

85 Blickle, Die Revolution des Gemeinen Mannes, S. 32.

86 Blickle, Die Revolution von 1525, S. 40-48. 
Fürstabtes von Kempten, Friedrich von Laubenberg, ${ }^{87}$ noch tiefer in die Leibeigenschaft hinabgedrückt. ${ }^{88}$

Die Allgäuer*innen schlossen sich am 27. Februar 1525 zu einem Haufen zusammen. Bereits vor Weihnachten 1524 hatten die Baltringer*innen ebenfalls einen solchen gebildet. Im Gebiet am Bodensee gab es eine Reihe kleinerer Zusammenschlüsse, die Anfang März 1525 im Seehaufen aufgingen. Sie planten keinen gewaltsamen Umsturz, sondern wollten durch diese Zusammenschlüsse lediglich ihre Position in den Verhandlungsgesprächen verstärken. ${ }^{89}$

Die Baltringer*innen unter der Führung Ulrich Schmids ${ }^{90}$ legten dem Schwäbischen Bund am 16. Februar rund dreihundert lokale Beschwerdeschriften vor. Rund 90 Prozent der Bäuerinnen und Bauern klagten über die Leibeigenschaft und 81 Prozent über die Entfremdung von Jagd-, Fischerei- und Allmende-Rechten. ${ }^{91}$

Die lokalen Beschwerdeschriften ${ }^{92}$ wurden von Sebastian Lotzner, ${ }^{93}$ einem Kürschnergesellen, einheitlich zusammengefasst. ${ }^{94}$ Das Ergebnis waren die Zwölf Artikel ${ }^{95}$ - laut Blickle „Beschwerdeschrift, Reformprogramm und politisches Manifest zugleich".96 Sie forderten die Abschaffung der Leibeigenschaft und das Recht der Gemeinden, Pfarrer selbst ein- und abzusetzen. Die Forderungen deckten sich zum großen Teil mit jenen vorangegangener Aufstände: Freigabe von Jagd und Fischerei, Rückgabe entfremdeter Nutzungsrechte, Reduzierung der Abgaben und Dienste, Abschaffung der Todesfallabgabe. Das radikal Neue war die Legitimationsgrundlage: Durch die Berufung auf das Evangelium und das "Göttliche Recht" als verbindliche Basis für die Neuordnung der Gesellschaft konnte das bestehende Recht außer Kraft gesetzt werden. ${ }^{97}$ Grundsätzlich ließen die bäuerlichen Forderungen die wirtschaftliche und politische Vorrangstellung des Adels bestehen, doch die Abgaben sollten auf ihre Rechtmäßigkeit hin überprüft werden. ${ }^{98}$

87 Friedrich von Laubenberg († 1434) war von 1405 bis zu seinem Tod Fürstabt von Kempten. Siehe: Friedrich von Laubenberg, in: Wikipedia. Die freie Enzyklopädie, 27. 12. 2017, [https://de.wikipedia.org/wiki/Friedrich_von_ Laubenberg], eingesehen 5. 2. 2019.

88 Franz, Der deutsche Bauernkrieg, S. 10-13.

89 Claudia Ulbrich, Oberschwaben und Württemberg, in: Peter Blickle/Horst Buszello/Rudolf Endres (Hrsg.), Der deutsche Bauernkrieg, S. 97-133, hier S. 97-105; Adolf Waas, Der Bauernkrieg. Die Bauern im Kampf um Gerechtigkeit 1300-1525, München o. J., S. 170-173.

90 Ulrich Schmid († vor 1541), Leibeigener des Zisterzienserinnenklosters Heggbach, war ab 1525 Hauptmann des Baltringer Haufens. Der vorreformatorischen Frömmigkeitsbewegung nahestehend, ist seine Rolle im Bauernkrieg höchst umstritten, zumal er sich nicht auf das "göttliche Recht" bezog und für eine gewaltlose Lösung des Konflikts plädierte. Peter Kissling, Schmid(t) (genannt Schmid von Sulmingen), Ulrich (Huldrich), in: Neue Deutsche Biographie, Bd. 23, Berlin 2007, S. 155.

91 Blickle, Die Revolution von 1525, S. 36.

92 Abdruck einer Auswahl von Beschwerdeschriften aus Oberschwaben in: Franz (Hrsg.), Quellen zur Geschichte des Bauernkrieges, S. 152-167.

93 Ebd.

94 Ebd.

95 Ebd., S. 174-179.

96 Blickle, Die Revolution von 1525, S. 23.

97 Winfried Becker, "Göttliches Wort", "Göttliches Recht", "göttliche Gerechtigkeit". Die Politisierung theologischer Begriffe?, in: Blickle (Hrsg.), Revolte und Revolution in Europa, S. 232-263.

98 Buszello, Der deutsche Bauernkrieg von 1525 als politische Bewegung, S. 63. 
Den ZwölfArtikeln kam eine große Bedeutung im Verlauf des Bauernkriegs zu, da sie die Funktion einer integrativen Programmschrift einnahmen und prinzipiell für alle Bäuerinnen und Bauern des Reiches als Grundlage für den Protest gegen die herrschende Obrigkeit dienen konnten. Sie hatten insofern auch eine mobilisierende Wirkung. Der Buchdruck machte es möglich, Flugschriften schnell und relativ kostengünstig zu verbreiten - die auf den Titelseiten vieler Drucke abgebildeten Holzschnitte sprachen die landwirtschaftlichen Stände auf einer emotionalen Ebene an. Innerhalb weniger Wochen erlebten die Zwölf Artikel 25 Drucke mit einer Gesamtauflage von ca. 25.000 Exemplaren. Interessant ist, dass sie in Wittenberg, dem Zentrum der lutherischen Reformation, nicht gedruckt wurden. ${ }^{99}$

Während die Bäuerinnen und Bauern aus dem Allgäu und dem Seehaufen ein militärisches Beistandsbündnis für die Zeit des Aufstands schließen wollten, drängten die Baltringer*innen auf die Bildung eines genossenschaftlichen Bundes, dem man sich durch Eid auf die Bundesordnung anschließen konnte. Mit der "Christlichen Vereinigung" wurde am 7. März ein politisches Gebilde geschaffen, das überregional agierte und durchaus als Eidgenossenschaft bezeichnet werden konnte. ${ }^{100}$ Den Kaiser wollte man so lange anerkennen, wie er umgekehrt die Existenz des Bundes akzeptierte. ${ }^{101}$ Die Zwölf Artikel und die Bundesordnung spielen noch heute im Geschichtsbewusstsein (Süd-)Deutschlands eine große Rolle: Der ehemalige deutsche Bundespräsident Johannes Rau sah in den Zwölf Artikeln die „Überzeugung von der Universalität der Menschenrechte".102

Erst durch den Abschluss des Weingartner Vertrags am 17. April 1525 zwischen den oberschwäbischen Bauerngruppierungen und dem „Bauernjörg”, Georg III. Truchsess von Waldburg-Zeil, ${ }^{103}$ dem Anführer des Schwäbischen Bundes, konnte der Aufstand beendet werden. ${ }^{104}$

\subsection{Thüringen: Müntzers radikale Reformation und die Reaktion Luthers}

Die Aufstandswelle erfasste auch Thüringen, wo mit Thomas Müntzer105 ein prominenter Reformator den Verlauf maßgeblich beeinflusste, der eine deutlich radikalere Vorstellung für die Neugestaltung der Gesellschaft hatte als die oberschwäbischen Bauernhaufen.

Das Territorium war in der Vergangenheit Schauplatz vieler Rivalitätskämpfe. 1485 wurde im Präliminärvertrag zu Leipzig die Teilung der sächsischen Gebiete in einen ernes-

99 Günter Vogler, Der revolutionäre Gehalt und die räumliche Verbreitung der oberschwäbischen Zwölf Artikel, in: Blickle (Hrsg.), Revolte und Revolution in Europa, S. 206-231, hier S. 209-210.

100 Buszello, Die Staatsvorstellung des "gemeinen Mannes“ im deutschen Bauernkrieg, S. 284.

101 Blickle, Die Revolution von 1525, S. 196.

102 Bundesregierung, Bulletin 16-1 vom 14. März 2000. Rede von Bundespräsident Johannes Rau bei der Feier "475 Jahre Zwölf Memminger Bauernartikel“ am 10. März 2000 in Memmingen, O. D., [https://www.bundesregierung. de/Content/DE/Bulletin/2000/16-1_Rau.html], eingesehen 5. 2. 2019.

103 Lebte von 1488 bis 1531. Zu seiner Person siehe: Peter Blickle, Der Bauernjörg. Feldherr im Bauernkrieg. Georg Truchsess von Waldburg. 1488-1531, München 2015.

104 Bernd Moeller, Deutschland im Zeitalter der Reformation (Deutsche Geschichte 4), Göttingen 1981², S. 94.

105 Lebte etwa von 1490 bis 1525. Günter Vogler, Müntzer, Thomas, in: Neue Deutsche Biographie, Bd. 18, Berlin 1997, S. 547-550. 
tinischen und in einen albertinischen Territorialkomplex der Wettiner*innen beschlossen. Der mittlere und niedere Adel errechnete sich dadurch Chancen und schaffte es in vielen Fällen, die Herrschaft über kleinere Gebiete zu übernehmen. Ab 1517 kam bei diesen Lagerbildungen noch die Frage hinzu, ob die Reformation Luthers unterstützt - wie der ernestinische Kurfürst von Sachsen, Friedrich der Weise ${ }^{106}$-, oder ob sie bekämpft werden sollte, wie dessen Vetter Georg der Bärtige ${ }^{107}$ meinte. Die Leidtragenden dieser undurchsichtigen Herrschaftsverhältnisse und Fehden waren die Stände der Bäuerinnen und Bauern. Das Fass zum Überlaufen brachten schließlich die Missernten und Hungersnöte der Jahre 1523/24. Den Bauerngruppen gesellte sich die Bürgerschaft hinzu, die wirtschaftlich zwar im Aufschwung war, sich politisch aber nicht genügend repräsentiert sah. ${ }^{108}$

In diese Stimmung der Unzufriedenheit hinein trat Thomas Müntzer. Er war nach 1517 in die Stadt Wittenberg gekommen, wo er persönlich mit Luther in Kontakt trat. Während seines Aufenthalts in Zwickau 1521 lernte er den Anführer der Zwickauer Prophet*innen, Nikolaus Storch, ${ }^{109}$ kennen, der zusammen mit seinen Anhängerscharen aus Wittenberg vertrieben worden war. ${ }^{110}$ Nach weiteren Stationen in Prag, Jena und Erfurt ließ er sich vorübergehend in Allstedt nieder. Müntzer, der in diesen Jahren einen Radikalisierungsprozess durchlief, sammelte dort einige Anhänger*innen um sich.

Während Luther nach wie vor die Zwei-Reiche-Lehre, also die strikte Trennung von Kirche und Staat, vertrat und die historische Ordnung als gottgegeben rechtfertigte, ${ }^{111}$ plädierte Müntzer dafür, die Welt von den „Ungläubigen“ zu reinigen und so die Ankunft Gottes vorzubereiten. Das hieß zunächst nicht gleich die radikale Absetzung aller Herrschaft: Solange diese der Reformation - und damit war nicht die Wittenbergische gemeint - nichts in den Weg stellte, sollte sie bestehen bleiben. ${ }^{112}$ Darauf wies er die ernestinischen Fürst*innen in der „Fürstenpredigt" vom 13. Juli 1524 hin. Luther wurde von Müntzer als „wittenbergerischer Papst“ und Fürstendiener bezeichnet, der alle unterdrückte, die sich ihm nicht unterordnen wollten und dem Adel „das Maul wohl mit Honig bestrichen" hätte. ${ }^{113}$

Die Zerstörung der Marienkapelle in Mallerbach markierte den Beginn des Aufstandes in Thüringen. Müntzer und seine Anhängerschaft, die sich im „Ewigen Bund Gottes”

106 Lebte von 1463 bis 1525. Friedrich Hermann Schubert, Friedrich III. der Weise, in: Neue Deutsche Biographie, Bd. 5, Berlin 1961, S. 568-572.

107 Lebte von 1471 bis 1539. Elisabeth Werl, Georg der Bärtige, in: Neue Deutsche Biographie, Bd. 6, Berlin 1964, S. 224-227.

108 Rudolf Endres, Thüringen, in: Blickle/Buszello/Endres (Hrsg.), Der deutsche Bauernkrieg, S. 154-176, hier S. 155157.

109 Paul Tschackert, Storch, Nicolaus, in: Allgemeine Deutsche Biographie, Bd. 36, Leipzig 1893, S. 442-445.

110 Siegfried Hoyer, Die Zwickauer Storchianer. Vorläufer der Täufer?, in: Jahrbuch für Regionalgeschichte 13 (1986), S. 60-78.

111 Carl Hinrichs, Luther und Müntzer. Ihre Auseinandersetzung über Obrigkeit und Widerstandsrecht (Arbeiten zur Kirchengeschichte 29), Berlin 1952, S. 33.

112 Dülmen, Reformation als Revolution, S. 96.

113 Günther Franz/Paul Kirn (Hrsg.), Thomas Müntzer. Schriften und Briefe. Kritische Gesamtausgabe (Quellen und Forschungen zur Reformationsgeschichte 33), Gütersloh 1968, S. 341. 
zusammenschloss, zogen weiter in die Stadt Mühlhausen, die als operationale Basis dienen sollte. Es kam so weit, dass die Aufstände Kurfürst Friedrich so schwer beschäftigten, dass er den Bauernkrieg als Folge seines eigenen Verhaltens, ja sogar als Strafe Gottes bezeichnete. ${ }^{114}$ Luther antwortete dem Aufstand mit der Schrift "Wider die Mordischen und Reubischen Rotten der Bawren"115 und rief darin die Fürst*innen auf, ihn niederzuschlagen. In der Schlacht von Frankenhausen am 15. Mai 1525 wurden die Truppen der Bäuerinnen und Bauern besiegt - 5.000 Menschen wurden getötet; auf der Seite der Fürst*innen waren nur sechs Gefallene zu verzeichnen. Müntzer selbst wurde unter der Folter ein katholisches Bekenntnis abgerungen. Am 27. Mai wurde er in Mühlhausen enthauptet. ${ }^{116}$

In einem Tischgespräch aus dem Jahr 1533 gab Luther seine Mitschuld am Tod Müntzers und der Niederschlagung der Aufstände der Bäuerinnen und Bauern zu. Er rechtfertigte sein hartes Vorgehen damit, dass er sich von einer radikalen Reformation abgrenzen wolle und nach wie vor die Trennung des geistlichen und politischen Bereiches vorsah. Gleichzeitig war ihm klar, dass er sich dadurch die Unterstützung der Fürst*innen sicherte. Er meinte: „Sic occidi Muncerum etiam, der todt ligt auff meim hals. Feci autem ideo, quia ipse voluit occidere meum Christum."117

\subsection{Tirol: Michael Gaismairs "Landesordnung"}

In der Grafschaft Tirol gab es mit dem Landesfürsten, dem Fürstbischof von Brixen und dem Fürstbischof von Trient mehrere politische Akteure. Das Land hatte unter Kaiser Maximilian I. mit einer Reihe von Seuchen, Hungerkrisen, Überschwemmungen und Kriegen zu kämpfen. Sogar der kaiserliche Diplomat Gregor Angerer sprach davon, dass die Bevölkerung durch „teglich neue steueren (und) bestendigen kriegszug“ zu leiden hatte. ${ }^{118}$ Während die Landwirtschaft stagnierte, erlebte der Bergbau einen beträchtlichen Aufschwung. Bereits unter Sigmund dem Münzreichen war das Kaufmannsgeschlecht der Fugger*innen in die Montanwirtschaft eingestiegen. Von diesem Aufschwung profitierten allerdings nur kleine Teile der Gesellschaft, so z. B. die Familie Gaismair. Michael Gaismairs Vater Jakob war ursprünglich Bergbauer in Tschöfs bei Sterzing und stieg dann in den Bergbau ein, der von Herzog Sigmund von Hall ins Wipptal und weiter ins südliche Eisacktal ausgedehnt wurde. Dort erhielt er als Tagwerker zwölf Kreuzer pro Tag und erwarb von dem verdienten Geld nacheinander 18 Bergwerkstollen. Von 1510 bis zu seinem Tod 1515 trat Jakob als Kreditgeber des Landeshauptmanns an der Etsch, Leonhard von Völs, auf. Seine Söhne Hans und Michael begannen ihre Laufbahn ebenfalls als Gewerken. ${ }^{119}$

114 Dülmen, Reformation als Revolution, S. 153

115 Martin Luther, Wider die Mordischen und Reubischen Rotten der Bawren, Wittenberg 1525,o. D. [https://books. google.at/books?id=zgLkECeARksC\&printsec=frontcover\&hl=de\&source=gbs_ge_summary_r\&cad=0\#v=onepa ge\&q\&f=false], eingesehen 5. 2. 2019

116 Endres, Thüringen, S. 173-174.

117 Ernst Kroker (Hrsg.), D. Martin Luthers Werke. Kritische Gesamtausgabe. Tischreden, Bd. 1, Weimar 1912, S. 195.

118 Bücking, Michael Gaismair, S. 28-30.

119 Bücking, Michael Gaismair, S. 144-146. 
1522 wurde mit Erzherzog Ferdinand I. ${ }^{120}$ ein Zwanzigjähriger, der zu diesem Zeitpunkt der deutschen Sprache noch nicht mächtig war, zum Landesfürsten ernannt. Er und sein Hofstaat - insbesondere der Jude Gabriel Salamanca' ${ }^{121}$ - wurden schnell zum Zielobjekt des Hasses. ${ }^{122}$ In den 1520er-Jahren war es bereits zu vereinzelten Aufständen und Protesten gekommen; 1525 gab es in Bozen antijüdische Ausschreitungen. ${ }^{123}$ Seit der Amtszeit Herzog Sigmunds hatten die Bauern- und Bürgerstände mehr Rechte erworben und in einzelnen Gebieten gab es Ansätze von bäuerlicher Selbstverwaltung. Die Gemeindegerichte traten als Konkurrenz zur landesfürstlichen Gewalt auf, doch durch die Aufnahme von Männern und Frauen aus den Reihen der Richter*innen, Pfleger*innen und Bürgermeister*innen in den niederen Adel konnte der Landesfürst deren Einfluss mindern. Trotzdem gab es immer noch regelmäßig stattfindende, $u$. $U$. auch bewaffnete Aufmärsche von Bauerngruppierungen - besonders an religiösen Feiertagen. 1519 wurde gegen die Bauernstände im Umland von Brixen ein Umzugsverbot festgelegt. ${ }^{124}$

Den Beginn des Bauernkriegs in Tirol markierte die Befreiung Peter Pässlers ${ }^{125}$ am 9. Mai 1525. Pässler hatte, nachdem ihm die Fischereirechte über einen Teich entzogen worden waren, trotz mehrfacher Mahnung einen bischöflichen Weiher ausgefischt, woraufhin er zum Tode verurteilt worden war. Einen Tag nach seiner Befreiung wurde eine Ver-sammlung in der Au von Milland einberufen, auf der ein Bürgerausschuss aus vier Personen bestimmt wurde. Einer davon war der ehemalige Sekretär des Bischofs Sebastian Sprenz, ${ }^{126}$ Michael Gaismair, der bereits vorher gegen das Urteil gegen Pässler protestiert hatte und deshalb in Ungnade gefallen war. Nach der Plünderung des Klosters Neustift wurde am 14. Mai von Gaismair die sogenannte „Erste Tiroler Landesordnung" verlesen. ${ }^{127}$ Darin wurde die Herrschaft des Adels nicht prinzipiell verworfen, sondern eine Gleichstellung aller Schichten unter landesfürstlicher Herrschaft angestrebt. Auf lokaler Ebene sollten die Gemeinden eine große Rolle spielen. ${ }^{128}$

Durch das Einberufen eines Landtages in Innsbruck am 12. Juni gelang es dem Erzherzog, dem Aufstand die Spitze zu nehmen. Dadurch, dass sich die Vertretung der

120 Buszello, Oberrheinlande, S. 74-77.

121 Gabriel von Salamanca-Ortenburg (1489-1539) war Generalschatzmeister und Hofkanzler unter der Regierung von Erzherzog Ferdinand und Graf von Ortenburg. Als Herr von Ehrenberg in Tirol zog er den Hass der Bevölkerung auf sich. Siehe: Hanns Schlitter, Ortenburg, Gabriel de Salamanca, in: Allgemeine Deutsche Biographie, Bd. 24, Leipzig 1887, S. 437-438.

122 Bücking, Michael Gaismair, S. 40.

123 Ebd., S. 32

124 Ebd., S. 47

125 Peter Pässler († 1527) war einer der Anführer des Tiroler Bauernkriegs. Er begleitete Gaismair auf seinem Zug nach Oberitalien. Im Oktober 1527 wurde er bei Venzone ermordet. Caroline Schnyder/Philipp Dubach, Päßler (Paßler), Peter, in: Neue Deutsche Biographie, Bd. 19, Berlin 1999, S. 756-757.

126 Sebastian Sprenz († 1525) war Hofrat Kaiser Maximilians I. und Kaiser Karls V. 1521 wurde er, unterstützt durch Erzbischof Matthäus Lang von Salzburg und Karl V., gegen den Willen des Tiroler Adels, der den Domherren Sigmund von Thun unterstützte, zum Bischof von Brixen gewählt. Sprenz sah sich angesichts der Bauernaufstände zur Flucht gezwungen, ehe er 1525 in Bruneck starb. Bernhard Ebneth, Sebastian II. Sperantius (Spren[t]z), in: Neue Deutsche Biographie, Bd. 24, Berlin 2010, S. 107-108.

127 Bücking, Michael Gaismair, S. 58-60.

128 Peter Blickle, Alpenländer, in: Blickle/Buszello/Endres (Hrsg.), Der deutsche Bauernkrieg, S. 191-214, hier S. 204207. 
Bäuerinnen und Bauern aufVerhandlungen einließ und die Gruppen nicht weiter plündernd durch die Gegend zogen, verpuffte die Dynamik des Aufstandes. Der kurzzeitig in Gefangenschaft genommene Gaismair flüchtete am 7. Oktober nach Graubünden, wo er in Kontakt mit Zwingli und dessen stark diesseitsbezogene Theologie kam, ${ }^{129}$ und radikalisierte sich. Als er zurückkehrte und den Aufstand der Salzburger*innen gegen Erzbischof Matthäus Lang ${ }^{130}$ unterstützte, forderte er das Abschütteln der landesfürstlichen Herrschaft. Er vertrat eine „Republikanismustheorie pragmatischen, nicht utopischen Zuschnitts", ${ }^{131}$ in der die Erträge aus der Verstaatlichung des Bergbaus und der Säkularisierung der Klöster die Basis für die Finanzierung des neuen Staates bilden sollten. Darüber hinaus plante Gaismair die Entsumpfung der Auenlandschaften, was einen beträchtlichen wirtschaftlichen Aufschwung gebracht hätte. Bücking identifiziert in dieser Gesellschaftsordnung allerdings auch autoritäre Züge sowie einen „Rückfall in ,Primitivismus (= Verdorfung), Uniformitätszwänge, Xenophobie, Ethnozentrismus, rigoristische Moral, Antikapitalismus, rationale Planung, zyklische Wiederholung des als richtig Erkannten".132

Die Truppen der Bäuerinnen und Bauern wurden am 2. Juli 1526 bei Radstadt geschlagen, Gaismair selbst gelang die Flucht nach Venedig. Am 15. April 1532 wurde er von einem bestochenen Paduaner auf seinem Landgut in Montegrotto ermordet. Tausend Gulden Kopfgeld waren auf inn angesetzt - das zeigt, welche Gefahr er in den Augen der habsburgischen Herrschaft darstellen musste. ${ }^{133}$

\section{Fazit}

Zusammenfassend lässt sich festhalten, dass sich die Ursachen des Bauernkrieges weitgehend mit jenen der spätmittelalterlichen Aufstände der Bäuerinnen und Bauern deckten. Dennoch spielte die Reformation für den Verlauf und die Legitimation der Handlungen eine zentrale Rolle: Mit der Berufung das Evangelium und auf das "Göttliche Recht" in Abgrenzung zum historischen Recht trat ein völlig neuer Aspekt hinzu. Die Reformator*innen, auf die sich die Bauernstände beriefen, waren eher Müntzer und Zwingli, weniger Luther.

Der Bauernkrieg war anfangs v. a. der Versuch, über den Verhandlungsweg den gemeinen Menschen mehr Rechte einzuhandeln. Dem herrschaftlichen sollte das genossenschaftliche Prinzip entgegengestellt werden. Die Zwölf Artikel und die Bundesordnung der oberschwäbischen Bauern und Bäuerinnen waren Verfassungsentwürfe, auf die sich die Bauern und Bäuerinnen auch in anderen Aufstandsgebieten beriefen. Die meisten Aufstände verliefen aber so, dass sich die zahlenmäßig in einigen Fällen überlegenen Bauerngruppierungen auf den Verhandlungsweg einließen, wodurch es

129 Blickle, Die Revolution von 1525, S. 243.

130 Anton Schindling, Matthäus Lang von Wellenburg, in: Neue Deutsche Biographie, Bd. 16, Berlin 1990, S. $394-397$.

131 Blickle, Die Revolution des gemeinen Mannes, S. 40.

132 Bücking, Michael Gaismair, S. 90.

133 Blickle, Alpenländer, S. 201-202. 
der Obrigkeit gelang, die mobilisierte Menge wieder auseinanderlaufen zu lassen oder mit neuen militärischen Kräften niederzuschlagen.

Trotz der breiten Rezeption der Zwölf Artikel fehlte ein einheitliches Ziel. In der Regel blieben die Aufstände auf die jeweilige Herrschaft beschränkt - besonders in Gebieten fortgeschrittener Territorialisierung. Einzig in den Gebieten größerer Zersplitterung gab es eine Tendenz zu herrschaftsübergreifenden Aufständen - gedacht wurde an die Formierung und den Zusammenschluss der verschiedenen Haufen von Bäuerinnen und Bauern, die den Grundstein für eine Eidgenossenschaft legten. Insgesamt handelte es sich aber um verschiedene lokale und regionale Aufstände mit fehlendem Geschehenszusammenhang, sodass Bob Scribner zum Urteil kommt, dass es einen „lack of synchronisation in the development of the revolution, with the different phases misfiring like a poorly timed engine" gab. ${ }^{134}$ Auch die Idee, den Kaiser allein als Herrn anzuerkennen und alle Zwischeninstanzen aufzuheben, blieb nur auf einzelne Gebiete oder Akteurskreise beschränkt. Konzepte einer reichsweiten Reform wie jene des Mainzers Friedrich Weigand und des Franken Wendel Hipler, ${ }^{135}$ welche als revolutionär bezeichnet werden können, fanden kaum breitere Anerkennung. Zudem muss in Erinnerung gerufen werden, dass die Anführer*innen der Bauern und Bäuerinnen mit ihren z. T. unrealistischen Ideen in vielen Fällen über die Forderungen der Bevölkerung hinausgingen. ${ }^{136}$

Die Folgen des Bauernkriegs waren vielfältig, doch die Theorien der völligen Entrechtung der Bauern und Bäuerinnen in den folgenden Jahrhunderten ${ }^{137}$ und der Entwicklung absolutistischer Herrschaftsformen seit $1525^{138}$ wurden weitgehend entkräftet. ${ }^{139}$ Als unmittelbare Reaktion gab es in manchen Gebieten zwar gewaltsame Strafgerichte - die Zahl der getöteten Aufständischen wird mit über 70.000 beziffert. ${ }^{140}$ Auch mussten die Bauernstände in vielen Gebieten selbst für die Schäden aufkommen. Doch den Obrigkeiten wurde mit 1525 bewusst, dass die Basis ihrer Herrschaft auch labil war und dass sie der Bauernschaft entgegenkommen mussten, um sich deren Unterstützung zu sichern. Immerhin machte der Stand der Bäuerinnen und Bauern im 16. Jahrhundert rund 80 Prozent der Bevölkerung aus. ${ }^{141}$ In vielen Gebieten wurden die Forderungen der Bauernhaufen berücksichtigt und gesetzlich verankert - so auch in der Tiroler Landesordnung von 1532, in der 70 Prozent der Forderungen uneingeschränkt und 20 Prozent mit geringfügigen Modifikationen übernommen wurden. ${ }^{142}$

134 Bob Scribner, 1525 - Revolutionary Crisis?, in: Hagenmaier/Holtz (Hrsg.), Krisenbewußtsein und Krisenbewältigung in der frühen Neuzeit, S. 25-45, hier S. 40.

135 Gerd Wunder, Hipler, Wendel, in: Neue Deutsche Biographie, Bd. 9, Berlin 1972, S. 199.

136 Scribner, 1525 - Revolutionary Crisis?, S. 42.

137 Moeller, Deutschland im Zeitalter der Reformation, S. 101.

138 Peter Blickle, Die politische Entmündigung des Bauern. Kritik und Revision einer These, in: Blickle (Hrsg.), Revolte und Revolution in Europa, S. 298-312, hier S. 298.

139 Thomas Klein, Die Folgen des Bauernkrieges von 1525. Thesen und Antithesen zu einem vernachlässigten Thema, in: Hessisches Jahrbuch für Landesgeschichte 25 (1975), S. 65-116.

140 Moeller, Deutschland im Zeitalter der Reformation, S. 100.

141 Blickle, Die Revolution des gemeinen Mannes, S. 43.

142 Ebd. 


\section{Literatur}

Adam, Thomas, Joß Fritz - das verborgene Feuer der Revolution. Bundschuhbewegung und Bauernkrieg am Oberrhein im frühen 16. Jahrhundert (Veröffentlichungen der Historischen Kommission der Stadt Bruchsal 20), Ubstadt-Weiher 2002.

Andreas, Willy, Deutschland vor der Reformation. Eine Zeitenwende, Stuttgart $1959^{6}$.

Arnold, Klaus, Niklashausen 1476. Quellen und Untersuchungen zur sozialreligiösen Bewegung des Hans Behem und zur Agrarstruktur eines spätmittelalterlichen Dorfes, in: Mainfränkisches Jahrbuch für Geschichte und Kunst 36 (1984), S. 326-332.

Ders., Neues zu Niklashausen 1476, in: Franklin Kopitzsch/Rainer Postel (Hrsg.), Reformation und Revolution. Beiträge zum politischen Wandel und den sozialen Kräften am Beginn der Neuzeit. Festschrift für Rainer Wohlfeil zum 60. Geburtstag, Stuttgart 1989, S. 69-89.

Becker, Winfried, "Göttliches Wort", "Göttliches Recht", "göttliche Gerechtigkeit". Die Politisierung theologischer Begriffe?, in: Peter Blickle (Hrsg.), Revolte und Revolution in Europa. Referate und Protokolle des Internationalen Symposiums zur Erinnerung an den Bauernkrieg 1525 (Memmingen, 24.-27. März 1975) (= HZ Beiheft 4), S. 232-263.

Blickle, Peter, Alpenländer, in: Peter Blickle/Horst Buszello/Rudolf Endres (Hrsg.), Der deutsche Bauernkrieg, München u. a. 1995³, S. 191-214.

Ders., Der Bauernjörg. Feldherr im Bauernkrieg. Georg Truchsess von Waldburg. 14881531, München 2015.

Ders., Der Bauernkrieg. Die Revolution des Gemeinen Mannes (C. H. Beck Wissen 2103), München 1998.

Ders., Die politische Entmündigung des Bauern. Kritik und Revision einer These, in: Blickle (Hrsg.), Revolte und Revolution in Europa, S. 298-312.

Ders., Die Revolution von 1525, München-Wien 1983².

Borgolte, Michael, Sozialgeschichte des Mittelalters. Eine Forschungsbilanz nach der deutschen Einheit, München 1996.

Bücking, Jürgen, Der „Bauernkrieg“ in den habsburgischen Ländern als sozialer Systemkonflikt, 1524-1526, in: Geschichte und Gesellschaft (1975), Sonderheft 1, S. 168-192.

Ders., Michael Gaismair: Reformer - Sozialrebell - Revolutionär. Seine Rolle im Tiroler „Bauernkrieg” (1525/32) (Tübinger Beiträge zur Geschichtsforschung. Spätmittelalter und Frühe Neuzeit 5), Stuttgart 1978.

Bundesregierung, Bulletin 16-1 vom 14. März 2000. Rede von Bundespräsident Johannes Rau bei der Feier "475 Jahre Zwölf Memminger Bauernartikel” am 10. März 2000 in Memmingen, O. D., [https://www.bundesregierung.de/Content/DE/Bulletin/2000/16-1_Rau.html], eingesehen 5. 2. 2019. 
Buszello, Horst, Der deutsche Bauernkrieg von 1525 als politische Bewegung. Mit besonderer Berücksichtigung der anonymen Flugschrift An die Versamlung Gemayner Pawerschafft, Berlin 1969.

Ders., Die Staatsvorstellung des "gemeinen Mannes" im deutschen Bauernkrieg, in: Blickle (Hrsg.), Revolte und Revolution in Europa, S. 273-295.

Ders., Legitimation, Verlaufsformen und Ziele, in: Peter Blickle/Horst Buszello/Rudolf Endres (Hrsg.), Der deutsche Bauernkrieg, München u. a. 1995³, S. 281-321.

Ders., Oberrheinlande, in: Blickle/Buszello/Endres (Hrsg.), Der deutsche Bauernkrieg, S. 61-96.

Ders., ,Wohlfeile“ und „Teuerung“ am Oberrhein 1340-1525 im Spiegel zeitgenössischer erzählender Quellen, in: Peter Blickle (Hrsg.), Bauer, Reich und Reformation. Festschrift für Günther Franz zum 80. Geburtstag am 23. Mai 1982, Stuttgart 1982, S. 18-42.

Carl, Horst, Der Schwäbische Bund 1488-1534. Landfrieden und Genossenschaft im Übergang vom Spätmittelalter zur Reformation (Schriften zur südwestdeutschen Landeskunde 24), Leinfelden-Echterdingen 2000.

Dülmen, Richard van, Reformation als Revolution. Soziale Bewegung und religiöser Radikalismus in der deutschen Reformation, München 1977.

Endres, Rudolf, Franken, in: Blickle/Buszello/Endres (Hrsg.), Der deutsche Bauernkrieg, S. 134-153.

Ders., Thüringen, in: Blickle/Buszello/Endres (Hrsg.), Der deutsche Bauernkrieg, S. 154176.

Ders., Ursachen, in: Blickle/Buszello/Endres (Hrsg.), Der deutsche Bauernkrieg, S. 217253.

Engels, Friedrich, Zum „Bauernkrieg”, in: Institut für Marxismus-Leninimus beim Zentralkomitee der SED (Hrsg.), Marx-Engels-Werke, Bd. 21, Berlin 1962, S. 402-404.

Fast, Heinold (Hrsg.), Der linke Flügel der Reformation. Glaubenszeugnisse der Täufer, Spiritualisten, Schwärmer und Antitrinitarier (Klassiker des Protestantismus 4, Sammlung Dieterich 269), Bremen 1962.

Franz, Günther, Der deutsche Bauernkrieg, Darmstadt $1984^{12}$.

Ders., Quellen zur Geschichte des Bauernkrieges, München 1963.

Friedrich von Laubenberg, in: Wikipedia. Die freie Enzyklopädie, 27.12.2017, [https:// de.wikipedia.org/wiki/Friedrich_von_Laubenberg], eingesehen 5. 2. 2019.

Hamm, Berndt, Das Gewicht von Religion, Glaube, Frömmigkeit und Theologie innerhalb der Verdichtungsvorgänge des ausgehenden Mittelalters und der frühen Neuzeit, in: Monika Hagenmaier/Sabine Holtz (Hrsg.), Krisenbewußtsein und Krisenbewältigung in der frühen Neuzeit - Crisis in early modern Europe. Festschrift für Hans-Christoph Rublack, Frankfurt am Main u. a. 1992, S. 163-196. 
Hinrichs, Carl, Luther und Müntzer. Ihre Auseinandersetzung über Obrigkeit und Widerstandsrecht (Arbeiten zur Kirchengeschichte 29), Berlin 1952.

Hoyer, Siegfried, Die Zwickauer Storchianer. Vorläufer der Täufer?, in: Jahrbuch für Regionalgeschichte 13 (1986), S. 60-78.

Klein, Thomas, Die Folgen des Bauernkrieges von 1525. Thesen und Antithesen zu einem vernachlässigten Thema, in: Hessisches Jahrbuch für Landesgeschichte 25 (1975), S. $65-116$.

Kretzschmar, Robert, Waß ich thu, das handel ich uß des dectors kopf und rath. Zur Rolle des Markgröninger Pfarrers Dr. Reinhard Gaißlin im „Armen Konrad“. Mit einer Edition der Berichte des Vogts Philipp Volland, in: Sigrid Hirbodian/Robert Kretzschmar/Anton Schindling (Hrsg.) " Armer Konrad“ und Tübinger Vertrag im interregionalen Vergleich. Fürst, Funktionseliten und "Gemeiner Mann" am Beginn der Neuzeit (Veröffentlichungen der Kommission für geschichtliche Landeskunde in Baden-Württemberg, B/206), Stuttgart 2016, S. 63-96.

Kretzschmar, Robert/Rückert, Peter, Der „Arme Konrad“ in Württemberg 1514. Selbstverständnis, Artikulation und Kommunikation, in: Hirbodian/Kretzschmar/Schindling (Hrsg.), „Armer Konrad” und Tübinger Vertrag im interregionalen Vergleich, S. 33-62.

Laube, Adolf, Die Volksbewegung in Deutschland von 1470 bis 1517. Ursachen und Charakter, in: Blickle (Hrsg.), Revolte und Revolution in Europa, S. 84-98.

Marchal, Guy Paul, Die Ursprünge der Unabhängigkeit, in: Beatrix Mesmer (Hrsg.), Geschichte der Schweiz und der Schweizer, Basel 20064, S. 109-214.

Maurer, Hans-Martin, Der Arme Konrad als Schlüsselereignis württembergischer Geschichte, in: Uwe Jens Wandel (Hrsg.), Der Arme Konrad. Die Vorträge und Referate des Schorndorfer Symposions 1986, Schorndorf 1991, S. 8-25.

Moeller, Bernd, Deutschland im Zeitalter der Reformation (Deutsche Geschichte 4), Göttingen $1981^{2}$.

Oechsle, Ferdinand Friedrich, Beiträge zur Geschichte des Bauernkrieges in den schwäbisch-fränkischen Grenzlanden, Heilbronn 1830.

Ranke, Leopold von, Deutsche Geschichte im Zeitalter der Reformation, Berlin 1839.

Römer, Hermann, Die Anfänge Herzog Ulrichs und der Aufstand des Armen Konrad in Markgröningen, in: Hermann Römer (Hrsg.), Markgröningen im Rahmen der Landesgeschichte, Bd. 1., Markgröningen 1933, S. 190-229.

Sartorius, Georg Friedrich, Versuch einer Geschichte des deutschen Bauernkrieges oder der Empörung in Deutschland zu Anfang des sechszehnten Jahrhunderts, Berlin 1795.

Schmauder, Andreas, Württemberg im Aufstand. Der Arme Konrad 1514. Ein Beitrag zum bäuerlichen und städtischen Widerstand im Alten Reich und zum Territorialisierungsprozeß im Herzogtum Württemberg an der Wende zur frühen Neuzeit (Schriften zur südwestdeutschen Landeskunde 21), Leinfelden-Echterdingen 1998. 
Scribner, Bob, 1525 - Revolutionary Crisis?, in: Hagenmaier/Holtz (Hrsg.), Krisenbewußtsein und Krisenbewältigung in der frühen Neuzeit, S. 25-45.

Steinmetz, Max, Die dritte Etappe der frühbürgerlichen Revolution. Der deutsche Bauernkrieg 1524 bis 1526, in: Rainer Wohlfeil (Hrsg.), Der Bauernkrieg 1524-26. Bauernkrieg und Reformation (Nynmphenburger Texte zur Wissenschaft 21), München 1975, S. 65-89.

Stettler, Bernhard, Die Eidgenossenschaft im 15. Jahrhundert. Die Suche nach einem gemeinsamen Nenner, Zürich 2004.

Ulbrich, Claudia, Oberschwaben und Württemberg, in: Blickle/Buszello/Endres (Hrsg.), Der deutsche Bauernkrieg, S. 97-133.

Vogler, Günter, Der revolutionäre Gehalt und die räumliche Verbreitung der oberschwäbischen Zwölf Artikel, in: Blickle (Hrsg.), Revolte und Revolution in Europa, S. 206-231.

Ders., Revolte oder Revolution? Anmerkungen und Fragen zum Revolutionsproblem in der frühen Neuzeit, in: Stefan Ehrenpreis u. a. (Hrsg.), Wege der Neuzeit. Festschrift für Heinz Schilling zum 65. Geburtstag, Berlin 2007, S. 381-413.

Waas, Adolf, Der Bauernkrieg. Die Bauern im Kampf um Gerechtigkeit 1300-1525, München O. J.

Wendt, Georg Moritz, Der Fehler im System. Der „Arme Konrad" im Kontext der württembergischen Herrschaftsverdichtung, in: Hirbodian/Kretzschmar/Schindling (Hrsg.), „Armer Konrad" und Tübinger Vertrag im interregionalen Vergleich, S. 325-342.

Williams, George Huntston, The Radical Reformation. Sixteenth Century Essays and Studies, Kirksville 1992.

Wohlfeil, Rainer, Nachwort, in: Wohlfeil (Hrsg.), Der Bauernkrieg 1524-26, S. 280-282.

Zimmermann, Wilhelm, Allgemeine Geschichte des deutschen Bauernkrieges, Bd. 1, Stuttgart 1842.

\section{Nachschlagewerke}

Bock, Ernst, Dieter Graf von Isenburg, in: Neue Deutsche Biographie, Bd. 3, Berlin 1957, S. 668-669.

Buszello, Horst, Müller (genannt von Bulgenbach), Hans, in: Neue Deutsche Biographie, Bd. 18, Berlin 1997, S. 397-398.

Ebneth, Bernhard, Sebastian II. Sperantius (Spren[t]z), in: Neue Deutsche Biographie, Bd. 24, Berlin 2010, S. 107-108.

Flachenecker, Helmut, Rudolf II. von Scherenberg, in: Neue Deutsche Biographie, Bd. 22, Berlin 2005, S. 192-193. 
Franz, Günther, Gerber, Erasmus, in: Neue Deutsche Biographie, Bd. 6, Berlin 1964, S. 254-255.

Haug-Moritz, Gabriele, Ulrich I., Herzog von Württemberg, in: Neue Deutsche Biographie, Bd. 26, Berlin 2016, S. 600-601.

Kissling, Peter, Schmid(t) (genannt Schmid von Sulmingen), Ulrich (Huldrich), in: Neue Deutsche Biographie, Bd. 23, Berlin 2007, S. 155.

Kolmer, Lothar, Sebastian Lotzer, in: Biographisch-Bibliographisches Kirchenlexikon, Bd. 5, Herzberg 1993, Sp. 277-278.

Looz-Corswarem, Otto Graf von, Anton der Gute, in: Neue Deutsche Biographie, Bd. 1, Berlin 1952, S. 316.

Moeller, Bernd, Hubmaier, Balthasar, in: Neue Deutsche Biographie, Bd. 9, Berlin 1972, S. 703.

Schindling, Anton, Matthäus Lang von Wellenburg, in: Neue Deutsche Biographie, Bd. 16, Berlin 1990, S. 394-397.

Schlitter, Hanns, Ortenburg, Gabriel de Salamanca, in: Allgemeine Deutsche Biographie, Bd. 24, Leipzig 1887, S. 437-438.

Schnyder, Caroline/Dubach, Philipp, Päßler (Paßler), Peter, in: Neue Deutsche Biographie, Bd. 19, Berlin 1999, S. 756-757.

Schubert, Friedrich Hermann, Friedrich III. der Weise, in: Neue Deutsche Biographie, Bd. 5, Berlin 1961, S. 568-572.

Stolberg-Wernigerode, Otto Graf zu, Böhm (Beheme), Hans (Pauker von Niklashausen, Pfeiferhänsle), in: Neue Deutsche Biographie, Bd. 2, Berlin 1955, S. 382.

Tschackert, Paul, Storch, Nicolaus, in: Allgemeine Deutsche Biographie, Bd. 36, Leipzig 1893, S. 442-445.

Vogler, Günter, Müntzer, Thomas, in: Neue Deutsche Biographie, Bd. 18, Berlin 1997, S. $547-550$

Wandruszka, Adam, Ferdinand I., in: Neue Deutsche Biographie, Bd. 5, Berlin 1961, S. 81-83.

Werl, Elisabeth, Georg der Bärtige, in: Neue Deutsche Biographie, Bd. 6, Berlin 1964, S. 224-227.

Wunder, Gerd, Hipler, Wendel, in: Neue Deutsche Biographie, Bd. 9, Berlin 1972, S. 199.

\section{Quellen}

Franz, Günther (Hrsg.), Quellen zur Geschichte des Bauernkrieges (Ausgewählte Quellen zur deutschen Geschichte der Neuzeit. Freiherr vom Stein-Gedächtnisausgabe 2), Darmstadt 1963. 
Franz, Günther/Kirn, Paul (Hrsg.), Thomas Müntzer. Schriften und Briefe. Kritische Gesamtausgabe (Quellen und Forschungen zur Reformationsgeschichte 33), Gütersloh 1968.

Kroker, Ernst (Hrsg.), D. Martin Luthers Werke. Kritische Gesamtausgabe. Tischreden, Bd. 1, Weimar 1912.

Luther, Martin, Wider die Mordischen und Reubischen Rotten der Bawren, Wittenberg 1525, o. D. [https://books.google.at/books?id=zgLkECeARksC\&printsec=frontco

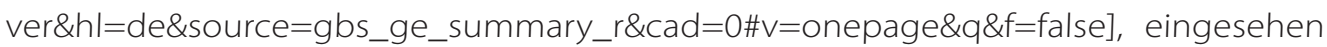
5. 2. 2019.

Schneider, Eugen (Hrsg.), Ausgewählte Urkunden zur Württembergischen Geschichte (Württembergische Geschichtsquellen 11), Stuttgart 1911.

Florian Ambach ist Student der Geschichte im 6. Semester an der Universität Innsbruck. Florian.Ambach@student.uibk.ac.at

\section{Zitation dieses Beitrages}

Florian Ambach, Der Bauernkrieg. Ein Systemkonflikt an der Wende vom Mittelalter zur Neuzeit, in: historia.scribere 11 (2019), S. 213-238, [http://historia.scribere.at], eingesehen 17.6.2019 (=aktuelles Datum).

(C) Creative Commons Licences 3.0 Österreich unter Wahrung der Urheberrechte der Autorlnnen. 